\title{
(6) OPEN ACCESS \\ Thou shalt not tweet unprofessionally: an appreciative inquiry into the professional use of social media
}

\author{
Ian Pereira, ${ }^{1}$ Anne Marie Cunningham, ${ }^{2}$ Katherine Moreau, ${ }^{3}$ Jonathan Sherbino, ${ }^{4}$ \\ Alireza Jalali ${ }^{3}$
}

- Additional material is published online only. To view please visit the journal online (http://dx.doi.org/10.1136/ postgradmedj-2015-133353).

${ }^{1}$ Queen's University, Kingston, Ontario, Canada

${ }^{2}$ Cardiff University School of Medicine, Cardiff, UK

${ }^{3}$ University of Ottawa, Ottawa, Ontario, Canada

${ }^{4}$ McMaster University

Hamilton, Ontario, Canada

Correspondence to Dr Alireza Jalali, Teaching Chair, Faculty of Medicine, University of Ottawa, uOttawa, 451 Smyth Rd, Ottawa, Ontario, Canada K1H 8M5; ajalali@uottawa.ca

Received 3 March 2015 Revised 9 June 2015 Accepted 23 July 2015 Published Online First 20 August 2015

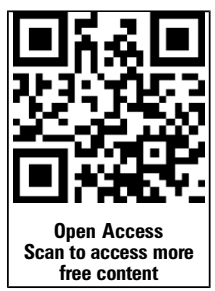

\section{SLinked}

- http://dx.doi.org/10.1136/ postgradmedj-2014-133230 - http://dx.doi.org/10.1136/ postgradmedj-2015-133300 - http://dx.doi.org/10.1136/ postgradmedj-2015-133358 - http://dx.doi.org/10.1136/ postgradmedj-2015-133612 - http://dx.doi.org/10.1136/ postgradmedj-2015-133686

\section{CrossMark}

To cite: Pereira I,

Cunningham AM, Moreau K, et al. Postgrad Med J

2015:91:561-564

\section{ABSTRACT}

Background Social media may blur the line between socialisation and professional use. Traditional views on medical professionalism focus on limiting motives and behaviours to avoid situations that may compromise care. It is not surprising that social media are perceived as a threat to professionalism.

Objective To develop evidence for the professional use of social media in medicine.

Methods A qualitative framework was used based on an appreciative inquiry approach to gather perceptions and experiences of 31 participants at the 2014 Social Media Summit.

Results The main benefits of social media were the widening of networks, access to expertise from peers and other health professionals, the provision of emotional support and the ability to combat feelings of isolation.

Conclusions Appreciative inquiry is a tool that can develop the positive practices of organisations and individuals. Our results provide evidence for the professional use of social media that may contribute to guidelines to help individuals realise benefits and avoid harms.

\section{INTRODUCTION}

Physicians, above all else, care for patients. Traditional views on medical professionalism focus on limiting motives and behaviours to prevent situations that may compromise this care. Digital age technologies, such as social media, have opened access to medical information and changed the nature of the patient-physician relationship. ${ }^{1-4}$ Professional responsibilities are often the same, but the logistics of meeting them are more difficult in this increasingly less private world. It is not surprising that social media are perceived as a threat to professionalism. ${ }^{5}{ }^{6}$ If professionalism is a social contract between medicine and society, ${ }^{7}$ and society is increasingly using social media, ${ }^{8}$ is it a professional responsibility of physicians to consider the rewards and risks of social media in the care of patients, society and themselves, as well as the education of learners?

Learners are already using social media to enrich education. A systematic review of social media in medical education showed that they improved knowledge, attitudes and skills among learners through higher engagement, feedback, collaboration and professional development. ${ }^{9}$ They also offer opportunities to improve learning at conferences, engage beyond formal education settings, keep current on literature and cultivate networks for career advancement. ${ }^{10-12}$ In addition, a growing number of patients and providers from around the world are learning together through online communities using blogs, twitter chats and journal clubs. ${ }^{13}$ Connections made online can translate to real-world opportunities for mentorship, scholarship and partnership. Increasingly, medical and healthcare conferences, meetings and organisations leverage social media to promote more effective engagement, networking, advocacy and learning among participants-both on-site and from a distance. ${ }^{14}$ As learners strive to keep current and relevant, social media can extend their education beyond borders. However, professional barriers exist.

Risks of using social media in medicine are prevalent and varied in the literature. Concerns include compromising confidentiality, eroding public trust and loosening accountability. ${ }^{15-17}$ Technical issues and lack of participation are also cited. ${ }^{8}$ There is uncertainty on how personal moral behaviours should be related to professionalism. ${ }^{18}$ In a study on the appropriateness of social media postings, physicians, trainees and the public agreed that obvious transgressions such as breaching confidentiality was inappropriate. However, they did not agree on other topics such as postings of alcohol and parties. ${ }^{16}$ Risks form the basis of most guidelines used today, but may have unintended consequences. ${ }^{19}$ In a study of perceptions of professionalism, trainees reported feelings of increased scrutiny and sacrificed freedom associated with a conflicted identity and resentment of guidelines and the administration behind them. ${ }^{20}$ Without addressing both sides of the social media story, enabling discussion and reaching consensus, risk-averse guidelines may widen the rift between administrators and the populations they seek to serve, in addition to neglecting its rewards.

More recently, there has been a trend towards medical professionalism guidance that includes its benefits. Canadian students have recognised the need to balance developing professional responsibilities with their online presence. ${ }^{21}$ The World Medical Association Junior Doctors Network worked with trainees around the world to develop a response to current guidelines. ${ }^{22}$ The UK's Royal College of General Practitioners has developed guidance through a collaborative process with a range of stakeholders. ${ }^{23}$ The Canadian Medical Protective Association even includes suggestions on how physicians can get started. ${ }^{24}$ However, the 
majority of evidence still focuses on the risks of using social media, leaving current guidelines imbalanced.

In this study we sought to develop evidence for the professional use of social media in medicine. We asked workshop participants to explore the topic through a positive lens using appreciative inquiry (AI).

\section{METHODS}

Participants

The workshop organising committee comprised two clinician educators and one medical trainee. There were 31 participants who were self-selected from the 90 attendees of the social media summit.

\section{Process}

A qualitative framework was used based on an AI approach to gather perceptions and experiences of the workshop participants.

\section{Appreciative Inquiry (Al)}

$\mathrm{Al}$ is a methodology that engages individuals with common experiences to take a positive approach to cultural change. It focuses on what works rather than fixing what may be wrong. This is encouraged through four phases in a cycle:

- Discovering best practices (Discovery)

- Envisaging processes that will work in the future (Dream)

- Designing effective development plans (Design)

- Implementing the proposed design (Delivery). ${ }^{17}$

\section{Workshop}

The workshop was conducted in five steps:

Step 1. Facilitators presented an overview of professionalism in social media to attendees based on a review of the literature.

Step 2. The AI framework was presented in the context of professionalism in social media.

Step 3. Participants were divided into four groups in a manner that allowed for diversity of representation in each group. Each group sequentially discussed the Discovery, Dream, Design and Delivery phases (the four-dimensional phases) and recorded their main ideas. Questions were used as prompts to stimulate discussion (box 1). Participants were encouraged to

\section{Box 1 Workshop questions}

Phase 1: Discovery

What do you consider to be the most positive trends, events and developments on social media and professionalism?

Phase 2: Dreaming

Imagine a time in the future when people look to our community as a leader in social media and professionalism. In this exciting future, what are the stakeholders doing? What are we most proud of having helped the community accomplish?

Phase 3: Design

What are the areas where you feel we could have the most impact on improving professionalism in a digital world?

Phase 4: Delivery

What changes could we make that would really encourage more people to use social media professionally? build on outcomes of previous phases to ensure continuity. Phases were changed every $15 \mathrm{~min}$.

Step 4. After all AI phases were completed, the facilitators invited each group to present their findings for each phase. Responses were reviewed by all participants and they were given the opportunity to add additional ideas.

Step 5. The main ideas were analysed (see online supplementary appendix A) and common themes were developed for each phase of the AI process.

\section{RESULTS}

Thirty attendees from 17 different organisations and institutions as well as four countries self-selected to participate in this workshop: 19 attending physicians; 5 resident doctors; 2 nonphysician educators; 2 administrators; 1 librarian; and 1 medical student.

The following themes were developed during each phase of the AI process. The main ideas from each group are included in online supplementary appendix A.

\section{Discovery: Discovery of best practices, the most positive trends, events and developments on social media and professionalism}

Participants believed the professional use of social media included building trusted online communities for learning, collaboration and to improve education resources. They cited examples of improving productivity (rather than detracting from it) by enabling access to educational resources when they wanted, from whom they wanted and from where they wanted across the world. Social media facilitated personal and professional development including finding mentorship for life choices, networking to build relationships and advocacy for their causes.

\section{Dream: Processes that will work in the future}

Looking ahead, participants envisaged supportive online medical education communities that provide equal opportunity for members to engage, recognise individual successes and leaders, help develop and sustain individual participation and recognise the importance of whole-person online interactions, including attention to individuals' well-beings. They wanted active permissive guidelines used universally not due to fear, but because of the clear benefits of social media, including improved safety and accountability for educators and trainees as well as the support of trusted medical education leaders. The participants thought that the benefits would outweigh risks due to the seamless integration of all social media platforms within their daily lives to increase productivity and well-being. They described how the positive impact would be clear through realised benefits in patient education and access to medical education resources from expertly curated material and the avoidance of unnecessary hierarchy.

\section{Design: Designing effective development plans, areas where we could have the most impact}

To achieve their dreams, participants felt that they needed methods to curate reliable medical education resources. They suggested that it would be effective to include information on using social media for peer reviewing available materials and for developing a system to provide users' and experts' endorsements of these materials. They discussed how the use of resources should be evidence-based, requiring scholarship in social media to develop metrics to assess real-world impact and facilitate 
continuous quality improvement. The participants described how the development of resources should be guided by education theory (including traditional theory and evolving theory) that may be tested against its impact on learners. These processes would require multidisciplinary and cross-sectoral input, including input from patients, positive guidelines, new leaders in social media, as well as education for educators and trainees on digital literacy.

\section{Delivery: Ensuring implementation through changes that we can make to ensure more people use social media professionally}

To ensure that the abovementioned designs are implemented, participants believed that they needed active guidelines. More specifically, they thought that leaders-comprising institutional champions from representative organisations-could draw on positive guidelines to empower individuals and facilitate cultural change with regard to social media. They described how this change could be facilitated by institutions accepting social media for academic advancement, peer review, Continuing Medical Education/Continuing Professional Development and performance assessments. Essentially, they discussed how education on social media could be delivered across the continuum of medical education and integrated with accepted frameworks (eg, CanMEDS).

\section{DISCUSSION}

We used the AI framework to describe the professional use of social media. The main benefits of social media were the widening of networks, access to the expertise of peers and other health professionals, and the provision of emotional support which can combat feelings of isolation. Others researching this area have found that health professionals report similar benefits. ${ }^{25}$ Of note, social media were not described as a place in which to interact with patients in the routine provision of healthcare.

Our results present an opportunity for those developing social media guidelines and education for health professions. Although AI is most often used as a tool for organisational development, it was used in this workshop to structure a diverse group of health professional leaders and enable them to reach consensus on ways for their organisations and membership bodies to embrace the professional use of social media. There was a consistent desire expressed for wide stakeholder involvement in the development of permissive rather than restrictive guidelines to aid health professionals. With these guidelines, strong leadership and role modelling along with constructive models of education could lead to a greater realisation of what some have already described as social media's 'golden age'. ${ }^{26}$

The workshop adopted the AI framework because it was thought that this would provide a positive environment where participants could consider how to move forward in an area which has been contentious. ${ }^{11}{ }^{15}$ However, this could also be seen as a limitation of the study, as the participants were reluctant to share negative experiences or attitudes towards social media.

We suggest that AI can be used by other organisations to further develop positive social media practices. We agree with Fenwick ${ }^{15}$ that more nuanced critical research is needed into how professionals deal with dilemmas and experiences in social media, but in the meantime there is potential to capitalise on the knowledge and insights of those who are already living and learning in these spaces to develop guidance that can help others realise the benefits and avoid the harms.

\section{Main messages}

- Professional use of social media includes building trusted online communities for learning, collaboration and to improve education resources.

- Main benefits of social media are the widening of networks and the provision of emotional support, which combat feelings of isolation for educators.

- Use of social media tools should be evidence-based, requiring scholarship in social media to develop metrics to assess real-world impact and facilitate continuous quality improvement.

\section{Current research questions}

- What are the best methods to curate reliable medical education resources using social media tools?

- How can medical educators deal with dilemmas and experiences in social media?

- How can academic leaders facilitate institutions to accept social media for academic advancement, peer review, Continuing Medical Education/Continuing Professional Development and performance assessments?

\section{Key references}

- Chretien KC, Goldman EF, Beckman L, et al. It's your own risk: medical students' perspectives on online professionalism. Acad Med 2010;85(10 Suppl):S68-71.

- Cheston CC, Flickinger TE, Chisolm MS. Social media use in medical education: a systematic review. Acad Med 2013;88:893-901.

- Fenwick T. Social media and medical professionalism: rethinking the debate and the way forward. Acad Med 2014;89:1331-4.

- Cunningham A. Social media and medical professionalism. Med Educ 2014;48:110-12.

- Kind T, Genrich G, Sodhi A, et al. Social media policies at US medical schools. Med Educ Online 2010;15.

Twitter Follow Anne Marie Cunningham at @amcunningham, Alireza Jalali at @arjalali and lan Pereira at @lanJohnPereira

Contributors All authors made substantial contributions to the conception or design of the work; or the acquisition, analysis, or interpretation of data for the work; drafting the work or revising it critically for important intellectual content; final approval of the version to be published; and agreement to be accountable for all aspects of the work in ensuring that questions related to the accuracy or integrity of any part of the work are appropriately investigated and resolved.

Competing interests None declared.

Provenance and peer review Not commissioned; externally peer reviewed.

Open Access This is an Open Access article distributed in accordance with the Creative Commons Attribution Non Commercial (CC BY-NC 4.0) license, which permits others to distribute, remix, adapt, build upon this work non-commercially, and license their derivative works on different terms, provided the original work is properly cited and the use is non-commercial. See: http://creativecommons.org/ licenses/by-nc/4.0/ 


\section{REFERENCES}

1 Blackmer J. Professionalism and the medical association. World Med J 2007;53:58-73.

2 Wynia MK, Latham SR, Kao AC, et al. Medical professionalism in society. N Eng/ J Med 1999;341:1612-16.

3 Physicians WPotRCo. Doctors in society. Medical professionalism in a changing world. Clin Med 2005;5(6 Suppl 1):S5-40.

4 Project MP. Medical professionalism in the new millennium: a physicians' charter. Clin Med 2002;2:116-18.

5 Walji M, Stanbrook M. Health professionalism must be ensured online and offline. CMAJ 2015; 187:547.

6 Chretien KC, Goldman EF, Beckman L, et al. It's your own risk: medical students' perspectives on online professionalism. Acad Med 2010;85(10 Suppl):S68-71.

7 Cruess SR, Cruess RL. Understanding medical professionalism: a plea for an inclusive and integrated approach. Medical education 2008;42:755-7.

8 Duggan M, Ellison N, Lampe C, et al. Social media update 2014. Pew Research Center, 2015.

9 Cheston CC, Flickinger TE, Chisolm MS. Social media use in medical education: a systematic review Academic medicine : journal of the Association of American Medical Colleges 2013;88:893-901.

10 Moran M, Seaman J, Tinti-Kane H. Teaching, learning, and sharing: how today's higher education faculty use social media. Babson Survey Research Group, 2011.

11 DeCamp M, Cunningham AM. Social media: the way forward or a waste of time for physicians? J $R$ Coll Physicians Edinb 2013;43:318-22.

12 Jalali A, Sherbino J, Frank J, et al. Social media and medical education: exploring the potential of Twitter as a learning tool. Int Rev Psychiatry 2015;27:140-6.

13 Katz M, Utengen A, Anderson $P$, et al. Disease-specific hashtags for online communication about cancer care. J Clin Oncol 2015;33.
14 Jalali A, Wood TJ. Tweeting during conferences: educational or just another distraction? Med Educ 2013;47:1129-30.

15 Fenwick T. Social media and medical professionalism: rethinking the debate and the way forward. Acad Med 2014;89:1331-4.

16 Jain A, Petty EM, Jaber RM, et al. What is appropriate to post on social media? Ratings from students, faculty members and the public. Med Educ 2014;48: 157-69.

17 Harrison B, Gill J, Jalali A. Social media etiquette for the modern medical student: a narrative review. Int J Med Students 2014;2:61-4.

18 Cunningham A. Social media and medical professionalism. Med Educ 2014:48:110-12.

19 Kind T, Genrich G, Sodhi A, et al. Social media policies at US medical schools. Med Educ Online Published Online: 15 Sep 2010. doi:10.3402/meo.v15i0.5324

20 Finn G, Garner J, Sawdon M. 'You're judged all the time!' Students' views on professionalism: a multicentre study. Med Educ 2010;44:814-25.

21 Brasg I. CFMS guide to medical professionalism: recommendations for social media. Ottawa: Canadian Federation of Medical Students, 2013.

22 Loh L, Bourque JM. Social media and medicine. World Medical Association, 2012.

23 Riley B, Gerada C. Royal College of General Practitioners Social Media Highway Code. 2013. http://www.rcgp.org.uk/ /media/Files/Policy/A-Z-policy/ RCGP-Social-Media-Highway-Code.ashx

24 Canadian Medical Protective Association. Social media: the opportunities, the realities. Canadian Medical Protective Association. Published Online: Oct 2014.

25 Panahi S, Watson J, Partridge H. Social media and physicians: exploring the benefits and challenges. Health Informatics J Published Online: 18 Jul 2014. doi:10.1177/ 1460458214540907

26 DeNicola N, Good M, Newton L. Back to the future: a history of ACOG in social media's golden age. Curr Opin Obstet Gynecol 2014;26:495-502. 